\title{
Practical Application of Fluorescence-based Image Analyzer for PCR Single-stranded Conformation Polymorphism Analysis Used in Detection of Multiple Point Mutations
}

\author{
Asako Takahashi-Fujii, Yoshizumi Ishino, Atsushi Shimada, and Ikunoshin Kato
}

Biotechnology Research Laboratories, Takara Shuzo, Shiga 520-21, Japan

\begin{abstract}
We present a practical application of polymerase chain reaction singlestrand conformational polymorphism (PCR-SSCP) using a fluorescence-based image analyzer. Fluorescence-labeled primers were used to amplify target sequences. After nondenaturing polyacrylamide gel electrophoresis using a conventional sequencing gel apparatus, the glass plate was directly transferred from the gel box to the image analyzer. High-quality computer storage of the imaging data allowed the image intensity to be quantified over a wide range. Various data bases can be constructed on the basis of this imaging data. This system is suitable for use in clinical examination settings, and its application, to detect ras gene mutations in human pancreatic cancer specimens, is presented.
\end{abstract}

olymerase chain reaction coupled with single-strand conformation polymorphism analysis (PCR-SSCP) is a rapid and efficient method for detecting mutations, even a single-base substitution, in genomic or cDNA sequences. The original method uses primers labeled with radioisotopes, and gel electrophoresis patterns are visualized by autoradiography. ${ }^{(1,2)}$ Mutations are detected as mobility shifts caused by a change in the conformation of single-stranded amplified fragments. The disadvantages of radioisotopes include the special facilities needed for their use and the potential hazards that radioisotopes present to living organisms. Therefore, a nonradioactive system is preferred for routine clinical examinations, especially for large numbers of samples. Silver staining for detection of SSCP has been presented. ${ }^{(3-5)}$ However, the sensitivity is not comparable to the radioisotopic method, and the images can be difficult to interpret. This is probably because the detection of DNA is not limited to the PCR product, and large amounts of DNA are loaded. Recently, a fluorescencebased method using an automated DNA sequencer has been reported. ${ }^{(6)}$ This method is sufficiently sensitive, and imaging data can be analyzed by computer. However, this system requires an automated sequencer for gel loading. Therefore, the sample number and the gelloading conditions are restricted. Moreover, there is some difficulty in determining optimal loading conditions because the photodetectors are fixed in the instrument and cannot be separated with gel electrophoresis.
In this report we present a new fluorescence-based SSCP (F-SSCP) using the image analyzer FMBIO-100,(7) which is more practical for wide use and is suitable for daily clinical application. Point mutations that were detected in some surgical specimens of human pancreatic cancers by this method are presented as an example.

\section{MATERIALS AND METHODS}

\section{Materials}

Enzymes for manipulating DNA and the c-Kiras gene primer set are the products of Takara Shuzo (Kyoto, Japan). Rhodamine $\mathrm{X}$ isothiocyanate (XRITC) was obtained from Molecular Probes (Eugene, OR). Genomic DNA from surgical specimens of human pancreatic cancers were a gift from Dr. M. Mariyama (National Cancer Center Research Institute, Tokyo, Japan). The image analyzer FMBIO-100 was from Takara Shuzo.

\section{Primer}

Universal primers M4 and RV, which hybridize to the region beside the multicloning site of M13 and pUC vectors, were labeled at the $5^{\prime}$ terminus with rhodamine $X$. The conjugation reaction was performed as described ${ }^{(8)}$ after removal of the 5'-amino-modified oligonucleotide from the DNA sequencer (380B, Applied Biosystems, Foster City, CA). Rhodamine-labeled oligonucleotides were purified by Sephadex G-50 followed by reverse-phase HPLC. The 
c-Ki-ras-specific primers were also labeled using the same procedure.

\section{Preparation of the Plasmids Containing a Mutagenized C-Ki-ras Gene Fragment}

Human genomic DNA was used as the template, and PCR was performed using the ras gene primer set ( $\mathrm{F} 1$ and $\mathrm{R} 1$ in Fig. 1). An amplified fragment containing codon 12 (108 bp long) was inserted into the Hincll site of pUC18. From this recombinant plasmid, six different mutants were prepared by PCR-based sitespecific mutagenesis as described earlier. ${ }^{(9)}$

\section{PCR Procedures}

For a model experiment using the plasmid template, $0.5 \mathrm{ng}$ of the plasmid DNA and 20 pmoles each of M4 and RV primer (both labeled with rhodamine $\mathrm{X}$ ) were added to the standard PCR mixture [total volume of $100 \mu \mathrm{l}$ containing 10 mм Trix- $\mathrm{HCl}$ (pH 8.3), $50 \mathrm{~mm} \mathrm{KCl}, 15 \mathrm{~mm}$ $\mathrm{MgCl}_{2}, 200 \mu \mathrm{M}$ of each deoxynucleotide triphosphate, and 2.5 units of Taq polymerase]. Twenty-five cycles ensued with temperature profiles of $30 \mathrm{sec}$ at $94^{\circ} \mathrm{C}, 2$ min at $55^{\circ} \mathrm{C}$, and $1 \mathrm{~min}$ at $72^{\circ} \mathrm{C}$ in a DNA thermal cycler (Perkin-Elmer Cetus, Norwalk, CT). Starting from genomic DNA, $0.1 \mu \mathrm{g}$ of DNA and each c-Ki-ras/12 forward and reverse primer (F1 and $R 1$ in Fig. 1) were added in the same reaction mixture described above except that Taq polymerase was added after incubation of the mixture for $10 \mathrm{~min}$ at $80^{\circ} \mathrm{C}$. The mixture was cycled 25 times, and some portion was analyzed by agarose gel electrophoresis; however, target DNA fragment could not be detected. One microliter of the mixture was then subjected to a second round of PCR. The c-Ki-ras/12 forward and reverse primers (rhodamine $X$ labeled or unlabeled), each 20 pmoles, were mixed, and 28 cycles were performed under the same conditions.

\section{Direct DNA Sequencing}

Two-step asymmetric PCR was performed to prepare single-stranded DNA. One microliter of the first PCR mixture from genomic DNA (described above) was mixed with 10 pmoles each of F1 and $R 1$ primers in $50 \mu$ l of the reaction mixture, and 30 cycles were performed with temperature profiles of $30 \mathrm{sec}$ at $94^{\circ} \mathrm{C}, 30 \mathrm{sec}$ at $55^{\circ} \mathrm{C}$, and $30 \mathrm{sec}$ at $72^{\circ} \mathrm{C}$ in a thermal cycler 9600 (Perkin-Elmer Cetus). The amplified fragment was purified by ultrafiltration (Suprec-02, Takara). From $30 \mu \mathrm{l}$ of the purified solution, $10 \mu \mathrm{l}$ was mixed with 25 pmoles of the forward primer, which was subjected to 30 cycles with the same temperature profile. The reaction mixture was again applied to Suprec-02, and, finally, $10 \mu \mathrm{l}$ of the purified solution was obtained. This amplified DNA was used as a template. As the sequencing primer, 3 pmoles of rhodamine X-labeled R2 primer (Fig. 1) was added. The dideoxy reaction was performed with Ladderman DNA polymerase ${ }^{(10)}$ for $6 \mathrm{~min}$ at $65^{\circ} \mathrm{C}$. For shorter range direct sequencing, the following deoxy/dideoxy termination mixes were

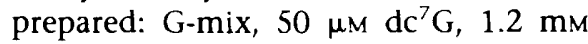
ddG, 0.4 mM dA, C, T; A-mix, $50 \mu \mathrm{M} d A, 3$ $\mathrm{mm}$ ddA, $0.4 \mathrm{~mm} \mathrm{dC}, \mathrm{T}, \mathrm{c}^{7} \mathrm{G}$; C-mix, 50 $\mu \mathrm{M} \mathrm{dC}, 1.2 \mathrm{~mm} \mathrm{ddC}, 0.4 \mathrm{~mm} \mathrm{dA}, \mathrm{T}, \mathrm{c}^{7} \mathrm{G}$; T-mix, $50 \mu \mathrm{M} \mathrm{dT}, 3.4 \mathrm{~mm}$ ddT, $0.4 \mathrm{mM} \mathrm{dA}$, $\mathrm{C}, \quad \mathrm{C}^{7} \mathrm{G}$. Sequencing gels were also scanned by FMBIO-100, and ladder images were obtained.

\section{RESULTS}

\section{Model SSCP}

The laser-excited fluorescence image analyzer FMBIO-100 is very useful for performing various experiments in the molecular biology field. ${ }^{(7)}$ Fluorescencelabeled compounds on a gel or a membrane (nitrocellulose, nylon) are excited with a green laser, and emitted light is converted to imaging data and analyzed by a microcomputer. To inves- tigate the application of FMBIO-100 to the imagery of the SSCP pattern, plasmid DNA with a c-Ki-ras gene fragment containing point mutations at codon 12 was used as starting materials and gel-loading conditions were investigated. Although temperature and the presence of denaturant are likely to cause a change in the conformation of single-stranded DNA, it is difficult to predict the best conditions for gel loading to separate each mutated fragment. In this experiment we attempted to separate seven amplified fragments, of 229 bp (ras fragment plus multicloning site). Figure 2 shows the effect of glycerol when electrophoresis was performed at room temperature $\left(20^{\circ} \mathrm{C}\right)$. Ten percent glycerol effectively separated each band. The effect of gel-loading temperature was then investigated in the $10 \%$ glycerol gel (Fig. $3)$. Every fragment had a different mobility with the gel containing $10 \%$ glycerol at $10^{\circ} \mathrm{C}$. Moreover, with FMBIO-100 analysis, the gel can be loaded again after it is scanned once. As shown in Figure 4 , most bands were separated after $2 \mathrm{hr}$. These results show that the F-SSCP can determine optimal conditions for the gel electrophoresis of each target DNA.

\section{Analysis of ras Genes in Human Pancreatic Cancers}

The F-SSCP was then applied to DNA samples from surgical specimens of human pancreatic cancers. The c-Ki-ras gene activation of human pancreatic cancers has been analyzed by RNase A

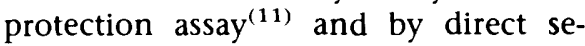
quencing. ${ }^{(12)}$ The region analyzed in this study and the primers used for PCR are shown in Figure 1. PCR-amplified fragments, 71 bp long, with rhodamine X-labeled F1 and R2 were analyzed. As a control, amplified fragments from mutant plasmids used in the model experiment were loaded on the gel in parallel. As shown in Figure $5 \mathrm{a}$, at least five samples (lanes $1-4,7$ ) of these seven surgical

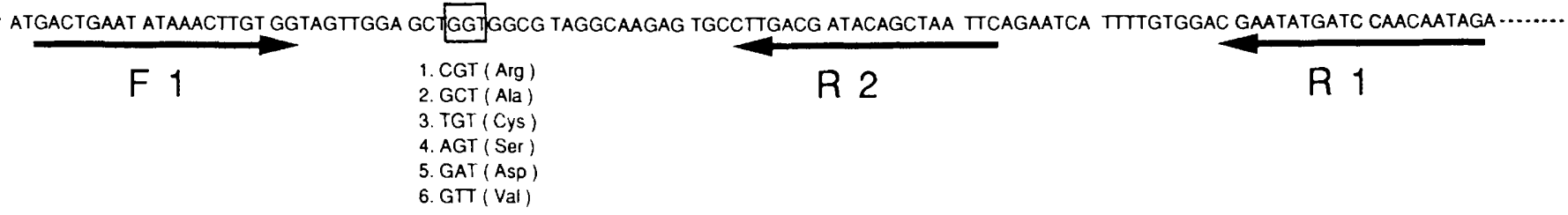

FICURE 1 Primers used for the PCR to amplify the c-Ki-ras gene fragment containing codon 12. 

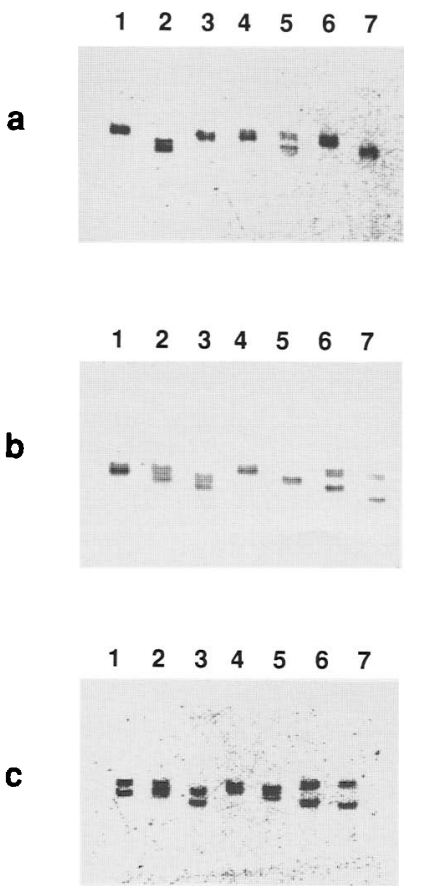

FIGURE 2 Effect of glycerol in the gel on the mobility of separated strands. The plasmids containing various mutants of the c-Ki-ras gene fragment were analyzed by PCR-SSCP. Electrophoresis was carried out at room temperature in a $5 \%$ polyacrylamide gel without glycerol $(a)$, and with $5 \%(b)$ and $10 \%(c)$ glycerol. (Lane 1) K12Gly (GGT); (lane 2) K12Arg (CGT); (lane 3) K12Ala (GCT); (lane 4) K12Cys (TGT); (lane 5) K12Ser (AGT); (lane 6) K12Asp (GAT); (lane 7) K12Val (GTT).

specimens had some mutations. Moreover, the type of mutation was estimated by comparing the mobilities with those of the control fragments (lanes 8-14). It was difficult to separate GAT from the normal sequence (GGT). The targeted region was then amplified with unlabeled F1 and rhodamine X-labeled R2 primer so as to detect only one strand from each allele. Figure $5 b$ shows clearer results. From this image, an Asp mutation was also detected in lane 5 despite the very weak signal. To confirm the nucleotide substitutions detected by mobility shifts of these single-stranded DNA fragments, DNA samples were directly sequenced by modified asymmetric PCR with a fluorescence primer. The sequencing ladders obtained from FMBIO-100 reading of samples $1-4$ and 7 showed the predicted heterozygosity (Fig. 6). That there was a mutated A band in the ladder of number 5 was not conclusive, probably because the surgical tissues contain a significant number of normal cells.

\section{DISCUSSION}

PCR-SSCP analysis is a simple, rapid, and efficient method for detecting point mutations. To establish this method as a standard procedure in clinical examination, a nonisotopic version is essential. F-SSCP with the Pharmacia A.L.F. automated DNA sequencer is an excellent method. ${ }^{(6)}$ However, this method requires a costly automated sequencer for gel electrophoresis, so that the sample number can be analyzed at the same time it is restricted $(<40)$. Maintenance costs (periodic replacement of the laser) are also high. Pharmacia A.L.F. is the only sequencer equipped with water-
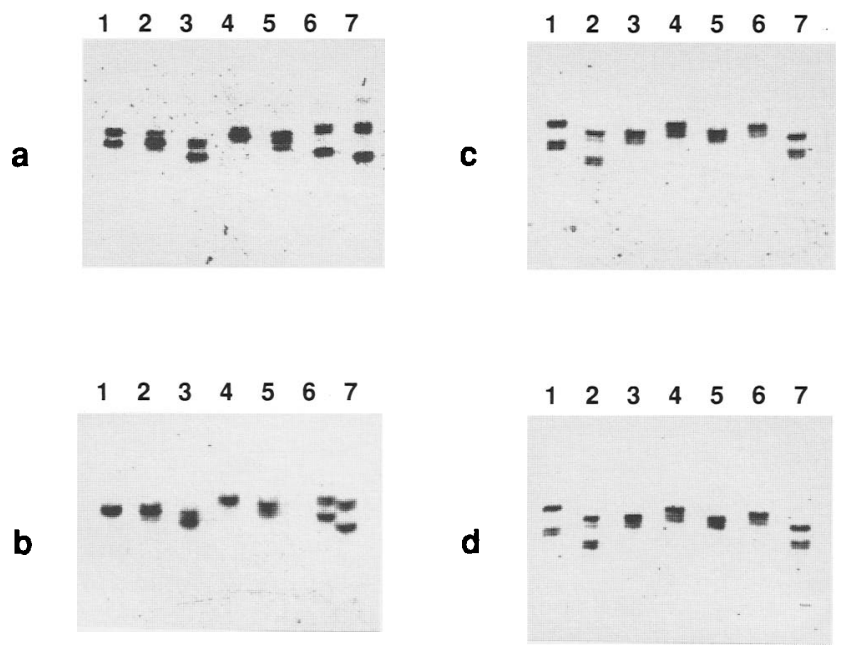

FIGURE 3 Effect of the gel-loading temperature on the mobility of separats stranded. Electrophoresis was carried out in a $5 \%$ polyacrylamide gel containing $10 \%$ glycerol at $10^{\circ} \mathrm{C}(a), 20^{\circ} \mathrm{C}(b)$, $25^{\circ} \mathrm{C}(c)$, and $30^{\circ} \mathrm{C}(d)$. Sample order is the same as in Fig. 2.

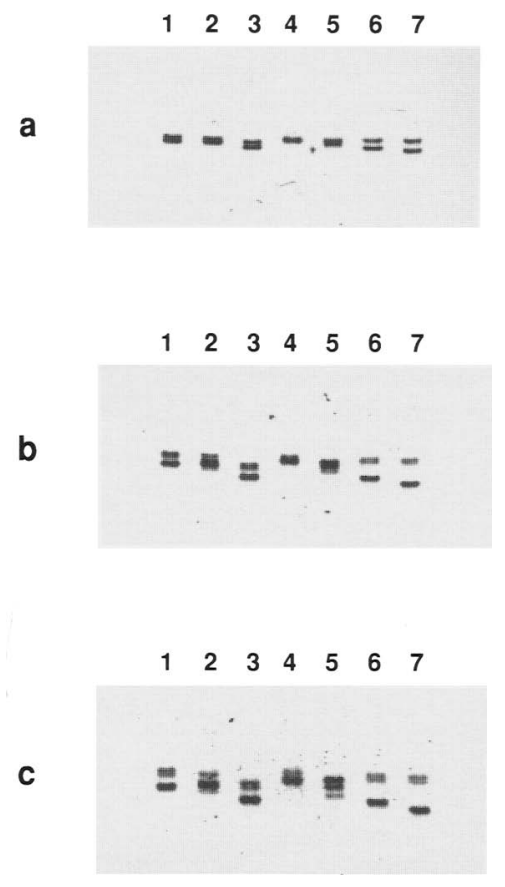

FIGURE 4 Effect of the gel-loading time on band separation. Electrophoresis was carried out in $5 \%$ polyacrylamide gel containing $10 \%$ glycerol at $10^{\circ} \mathrm{C}$ for $1 \mathrm{hr}$, which was scanned (a). The gel was loaded again for $1 \mathrm{hr}$ more $(b)$ and for an additional hour $(c)$. Sample order is the same as in Fig. 2.

jacketed electrophoresis apparatus; other commercial sequencers have difficulty changing the temperature during gel running. Here, we presented a F-SSCP, using the image analyzer FMBIO-100. ${ }^{(7)}$ An advantage of image analysis with the FMBIO is that any electrophoresis apparatus can be used and the image analyzer is only needed for scanning the gel plate, requiring only $10 \mathrm{~min}$. Therefore, more than one gel can be loaded in parallel when a large number of samples have to be analyzed. The sensitivity of this system is $<10^{-16}$ molecules per band, so the sensitivity is comparable to that of radioisotope labeling. PCR in this study was performed at the $100 \mu \mathrm{l}$ scale, but only $0.02 \mu \mathrm{l}$ of the reaction mixture was applied to the gel. The PCR scale can be reduced to $5 \mu \mathrm{l}$ to save materials. The mobility shift of single-stranded DNAs with DNA polymorphisms observed on a neutral polyacrylamide gel is very difficult to predict from the sequence, and the optimal conditions must be determined empirically. This new F-SSCP provides the most suitable method for determining the optimal conditions and for analyzing the large number of sam- 
$\begin{array}{lllllll}1 & 2 & 3 & 4 & 5 & 6 & 7\end{array}$

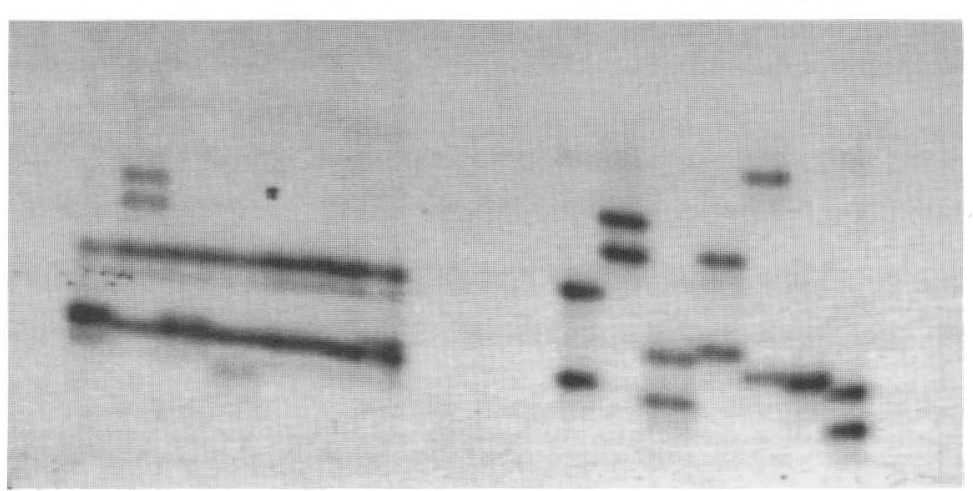

$\begin{array}{llllllllllllll}2 & 3 & 4 & 5 & 6 & 7 & & 8 & 9 & 10 & 11 & 12 & 13 & 14\end{array}$

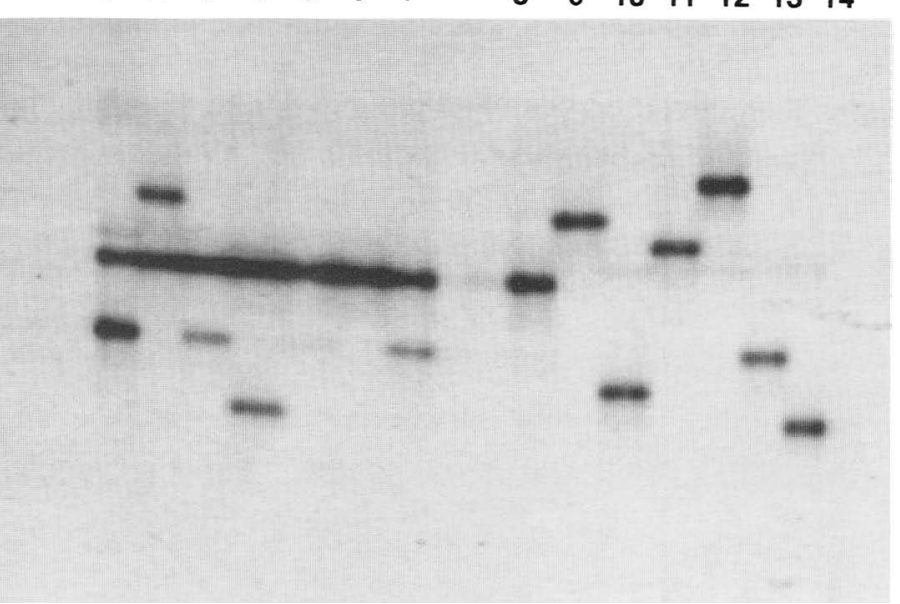

FIGURE 5 Detection of point mutations of the c-Ki-ras gene in surgical specimens of human pancreatic cancer. Genomic DNAs from seven different specimens were subjected to PCR-SSCP analysis. PCR was carried out with primers F1 and R2, where both were labeled $(a)$ or R2 was labeled $(b)$ with rhodamine $X$. Amplified fragments were applied to a $5 \%$ polyacrylamide gel and electrophoresed at $4^{\circ} \mathrm{C}$ (lanes $1-7$ ). Amplified fragments from the plasmid used in the model experiment (Figs. 2-4) were loaded in parallel on the same gel. The sample order of lanes 8-14 was the same as that in Figs. 2-4.

ples generated by clinical examinations. It is easier to judge whether there are mutations from the imaging data generated by the analyzer than from the output of the automated sequencer, because a raw band pattern is better visualized than a peak pattern. The imaging data from FMBIO can be entered directly into a computer and analyzed quantitatively. Many data bases consisting of imaging

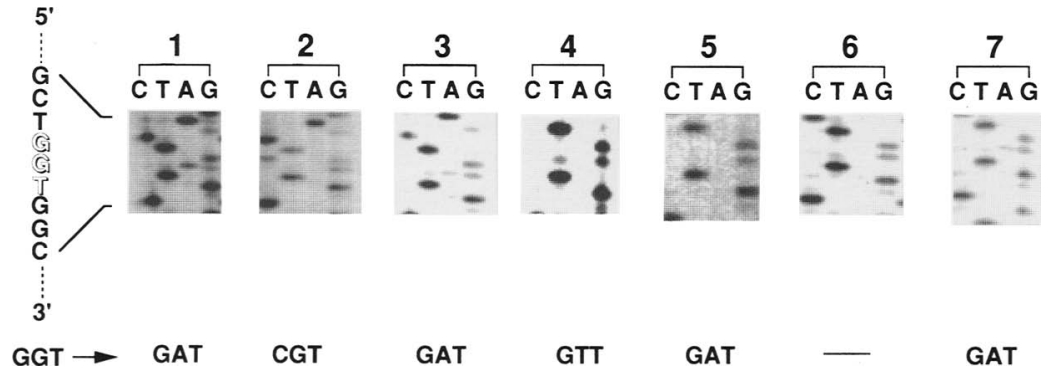

FICURE 6 Direct sequencing of the amplified fragments from surgical specimens used for PCR. SSCP. Amplified fragments that showed the mobility shifts seen in Fig. 5 were directly sequenced by asymmetric PCR. Fluorescence-labeled R2 primer was used for dideoxy termination reaction, and ladder images were obtained from scanning the gel with the FMBIO-100.

data can then be constructed. The FMBIO-100 instrument will be commercially available with world-wide availability in the near future and will facilitate routine clinical examinations.

\section{ACKNOWLEDGMENTS}

We thank Dr. M. Mariyama (National Cancer Research Institute) for providing genomic DNA from surgical specimens. We also thank Dr. K. Hayashi (National Cancer Research Institute) for critical reading of the manuscript.

\section{REFERENCES}

1. Hayashi, K. 1991. PCR-SSCP: A simpie and sensitive method for detection of mutations in genomic DNA. PCR Methods Applic. 1: 34-38.

2. Orita, M., Y. Suzuki, T. Sekiya, and K. Hayashi. 1989. A rapid and sensitive detection of point mutations and genetic polymorphisms using polymerase chain reaction. Genomics 5: 874-879.

3. Ainsworth, P.J., L.C. Surh, and M.B. Coulter-Mackie. 1991. Diagnostic single strand conformational polymorphism, (SSCP): A simplified non-radioisotopic method as applied to a Tay Sachs B1 variant. Nucleic Acids Res. 19: 405-406.

4. Dockorn-Dworniczak, B., B. Dworniczak, L. Brommelkamp, J. Bulles, J. Horst, and W. Bocker. 1991. Non-isotopic detection of single strand conformation polymorphism (PCR-SSCP). Nucleic Acids Res. 19: 2500 .

5. Mohabeer, A.J., A.L. Hiti, and W.J. Martin. 1991. Nonradioactive single strand conformation polymorphism (SSCP) using the Pharmacia "PhastSystem." Nucleic Acids Res. 19: 3154.

6. Makino, R., H. Yazyu, Y. Kishimoto, T. Sekiya, and K. Hayashi. 1992. F-SSCP: Fluorescence-based polymerase chain reaction-single-strand conformation polymorphism (PCR-SSCP) analysis. PCR Methods Applic. 2: 10-13.

7. Ishino, Y., J. Mineno, T. Inoue, H. Fujimiya, K. Yamamoto, T. Tamura, M. Homma, K. Tanaka, and 1. Kato. 1992. Practical applications in molecular biology of sensitive fluorescence detection by a laser-excited fluorescence image analyzer. BioTechniques 13: 936-943.

8. Smith, L.M., S. Fung, M.W. Hunkapiller, T.J. Hunkapiller, and L.E. Hood. 1985. The synthesis of oligonucleotides containing an aliphatic amino group at the $5^{\prime}$ terminus: Synthesis of fluorescent DNA primers for use in DNA sequence analysis. Nucleic Acids Res. 13: 2399-2412.

9. Ito, W., H. Ishiguro, and $Y$. Kurosawa. 1991. A general method for introducing a 
series of mutations into cloned DNA using the polymerase chain reaction. Gene 102: $67-70$.

10. Ishino, Y. 1992. Rapid and reliable DNA sequencing with a dideoxy sequencing kit. Am. Biotechnol. Lab. 10: 47.

11. Almoguera, C., D. Shibata, K. Forrester, J. Martin, and N. Arnheim. 1988. Most human carcinomas of the exocrine pancreas contain mutant c-Ki-ras genes. Cell 53: $549-554$.

12. Gonzalez-Cadavid, N.F., D. Zhou, H. Battifora, M. Bar-Eli, and M.J. Cline. 1989. Direct sequencing analysis of exon 1 of the c-Ki-ras gene shows a low frequency of mutations in human pancreatic adenocarcinomas. Oncogene 4: 1137-1140.

Received December 16, 1992; accepted in revised form March 15, 1993. 


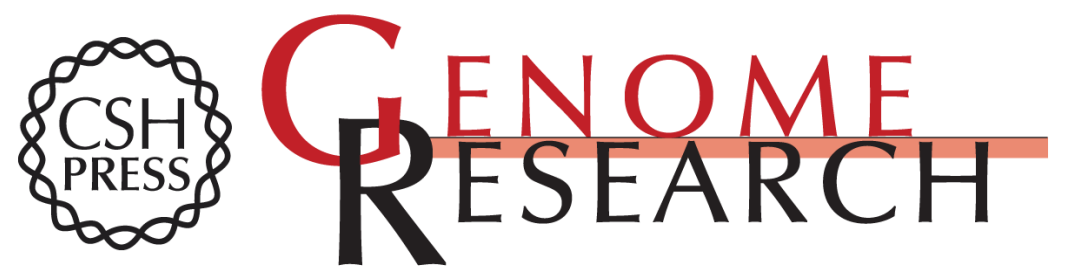

\section{Practical application of fluorescence-based image analyzer for PCR single-stranded conformation polymorphism analysis used in detection of multiple point mutations.}

A Takahashi-Fujii, Y Ishino, A Shimada, et al.

Genome Res. 1993 2: 323-327

Access the most recent version at doi:10.1101/gr.2.4.323

\section{License}

Email Alerting

Receive free email alerts when new articles cite this article - sign up in the box at the Service top right corner of the article or click here.

\section{Affordable, Accurate Sequencing.}

